\title{
Fabricación y caracterización de espumas de alúmina para aplicación en quemadores porosos radiantes
}

\section{Fabrication and characterization of alumina foams for application in radiant porous burners}

\author{
Herrera, A.M. ${ }^{1}$; Álvarez, O. ${ }^{2}$; Escobar, J. ${ }^{3}$; Moreno, V. ${ }^{3}$; \\ Oliveira Jr. A.A.M. ${ }^{3}$; Hotza, D. ${ }^{4}$
}

\author{
${ }^{1}$ Departamento de Engenharia Mecânica, Universidade Federal de Santa Catarina, \\ Florianópolis, Brasil \\ e-mail: veronicamorenoarguello@gmail.com; herreraalmanza@gmail.com; amir.oliveira@gmail.com \\ ${ }^{2}$ Departamento de Ingeniería Química, Universidad de Los Andes, Bogotá, Colombia \\ e-mail: oalvarez@uniandes.edu.co \\ ${ }^{3}$ Departamento de Ingeniería Mecánica, Universidad de Los Andes, Bogotá, Colombia \\ e-mail: jaiescob@uniandes.edu.co \\ ${ }^{4}$ Departamento de Engenharia Química, Universidade Federal de Santa Catarina, Florianópolis, Brasil \\ e-mail: dhotza@gmail.com
}

\section{RESUMEN}

En los quemadores radiantes, la fuente de calor requiere un medio poroso en donde se lleva a cabo la reacción de combustión, que hace más eficiente la transferencia de calor. En este trabajo se realizó un estudio de la reología de la suspensión de alúmina fina, cuyos parámetros de viscosidad y tixotropía fueron la base para la selección de la formulación más adecuada para la fabricación de espumas cerámicas por el método de réplica. Las espumas poliméricas precursoras presentaron mayor porosidad y permeabilidad, en respuesta a la presencia de paredes finas y $99 \%$ de celdas abiertas. La mayor resistencia mecánica a la compresión la obtuvo la formulación con mayor carga de sólidos, bajo las mismas condiciones de prueba.

Palabras claves: espumas cerámicas, réplica, alúmina, quemadores radiantes

\begin{abstract}
In radiant porous burners, the heat source requires a solid porous matrix where the combustion reaction takes place, in which the heat transfer is performed more efficiently. This work is based on a study of the alumina suspension rheology, where parameters as viscosity and tixotropy were the guide to select the appropriate formulation for the ceramic foam fabrication by the replica method. The precursor polymeric foams presented higher porosity and permeability, due to their thin walls and 99\% open cells. The highest mechanical strength under compression was obtained for the formulation with the highest solid fraction, under the same test conditions.
\end{abstract}

Keywords: ceramic foams, replica, alumina, radiant burners 


\section{INTRODUCCIÓN}

Durante la quema de combustible para la generación de energía se producen subproductos de alta toxicidad para el ambiente, razón suficiente para abordar esta problemática y buscar soluciones para disminuir esas emisiones. En esta clasificación se encuentran el monóxido de carbono (CO) e hidrocarburos sin oxidar, resultado de una combustión incompleta, y los gases tipo NOx y SOx. La producción de los NOx depende de las altas temperaturas que se presentan durante el proceso de combustión y del tiempo de residencia que estos gases permanecen a esas temperaturas [1, 2]. La generación de los SOx por su parte, depende de la cantidad de azufre que contenga el combustible empleado [3].

Para disminuir la proporción de los peligrosos gases NOx en el producto final del proceso de combustión, se debe tener en cuenta que a medida que la temperatura de combustión desciende, se da paso a una combustión incompleta y a la producción de CO. Fueron numerosas las estrategias que científicos e ingenieros desarrollaron para combatir el problema, dentro de las cuales es posible nombrar: recirculación de gases, combustión por etapas, extracción directa de calor de la región de combustión por interacción, y finalmente, extracción e intercambio de calor a través de una matriz sólida porosa [2].

Una matriz porosa o celular cuenta con una alta eficiencia en la transferencia de calor por radiación en el momento de atrapar la llama que se genera en la superficie del quemador. Dicha situación permite mantener bajas temperaturas de combustión y, por tanto, disminuir la emisión de gases NOx. Por esta razón y también por ventajas económicas y operacionales, diversos sectores de la industria han acoplado este sistema a sus procesos, tales como en el secado de papel y en diferentes etapas tanto en la industria alimenticia como en la cerámica tradicional [2-5].

Quemadores porosos radiantes son componentes utilizados como fuente de calor radiante durante la quema de combustible gaseoso [6,7]. La matriz sólida porosa promueve un precalentamiento de los reactivos de la combustión a través de conducción y radiación, causando un aumento de temperatura en la zona de reacción y una mayor conversión de la misma. De la combustión se genera una llama que es atrapada completamente en éste medio poroso y su calor es transportado por radiación, que a su vez conlleva a obtener mayores velocidades de llama [3, $\underline{4}$.

Las estructuras porosas cerámicas desplazaron a las metálicas en la aplicación de quemadores porosos por poseer mejor resistencia al operar a altas temperaturas y por tiempos prolongados, manteniendo la integridad de la misma sin presentar fracturas y/o degradación [3].

La alúmina es de los materiales más utilizados en aplicaciones que requieren temperaturas de operación significativamente altas, alrededor de $\operatorname{los} 1650^{\circ} \mathrm{C}$. Un factor clave que la diferencia de la zirconia, compuesto de gran similitud en cuanto a propiedades físicas (Tabla 1) y que también ha sido utilizada en quemadores porosos, es el precio por kilogramo siendo aproximadamente 1/3 del de la zirconia [6].

Tabla 1: Propiedades físicas de la alúmina y la zirconia [3].

\begin{tabular}{|c|c|c|}
\hline PROPIEDAD & ALÚMINA & ZIRCONIA \\
\hline Máxima temperatura de empleo $\left[{ }^{\circ} \mathrm{C}\right]$ & 1900 & 1800 \\
\hline Coeficiente de expansión térmica $\left(20-1000^{\circ} \mathrm{C}\right)\left[\times 10^{-6} \mathrm{~K}^{-1}\right]$ & 8 & $10-13$ \\
\hline Conductividad térmica a $20^{\circ} \mathrm{C}\left[\mathrm{W} \cdot \mathrm{m}^{-1} \cdot \mathrm{K}^{-1}\right]$ & $20-30$ & $2-5$ \\
\hline Conductividad térmica a $1000^{\circ} \mathrm{C}\left[\mathrm{W} \cdot \mathrm{m}^{-1} \cdot \mathrm{K}^{-1}\right]$ & $5-6$ & $2-4$ \\
\hline Emisividad a $2000 \mathrm{~K}$ & 0,28 & 0,31 \\
\hline
\end{tabular}

Existen tres técnicas principales para la fabricación de cerámicas celulares: espumación directa, sacrificio y réplica. Esta última es la técnica pionera en la fabricación de espumas cerámicas, por eso es la que cuenta con mayor información, experiencia, y tiene como gran ventaja su bajo costo si se compara con las otras técnicas [3]. El método consiste en impregnar una espuma de poliuretano (PU) $\mathrm{u}$ otro polímero, como poli(vinilcloruro) (PVC), poliestireno (PS) o celulosa [3], en una suspensión del material cerámico con el que se esté trabajando. Posteriormente es removido el exceso de suspensión al pasar la espuma a través de un sistema de calandras. Las espumas son secadas a temperatura ambiente; enseguida se procede a la eliminación de los compuestos orgánicos, que sigue un ciclo 
térmico de acuerdo con el análisis de termogravimetría (TGA) del polímero y finalmente la sinterización, en ciclos térmicos previamente establecidos de acuerdo al tipo de material cerámico con el que se esté trabajando. La remoción de los compuestos orgánicos debe realizarse muy lentamente, para evitar la formación de esfuerzos residuales que suelen causar una rotura del material cerámico, durante la volatilización del polímero [3,7].

El objetivo de este trabajo fue producir y caracterizar espumas cerámicas de alúmina para quemadores porosos radiantes. Para ello se realizó un estudio reológico de la suspensión de alúmina con el fin de determinar la formulación más adecuada para ser empleada en la fabricación de las estructuras celulares, por el método de réplica.

\section{MATERIALES Y MÉTODOS}

\subsection{Materias primas y aditivos}

Los componentes empleados en la fabricación de la suspensión se especifican en la Tabla 2.

Tabla 2: Materiales empleados para la fabricación de la suspensión de alúmina.

\begin{tabular}{c|c|c}
\hline MATERIAL & ESPECIFICACIÓN & PROVEEDOR \\
\hline Polvo cerámico & Alúmina calcinada S3G & Alcoa \\
\hline Dispersante & Darvan C-N (polimetacrilato de amonio) & RT Vanderbilt \\
\hline Ligante & PVA (alcohol polivinílico); 70000-100000 g/mol & Vetec Quimica \\
\hline Solvente & Agua destilada & UFSC \\
\hline
\end{tabular}

\subsection{Caracterización y preparación de las suspensiones}

Para la obtención de la dispersión de tamaño de partícula del polvo de alúmina, se prepararon $20 \mathrm{~g}$ de una suspensión de alúmina al $1 \%$ con $0,2 \%$ de dispersante. La medida del potencial zeta de alúmina se requirió $40 \mathrm{~g}$ de una suspensión de alúmina al 1\%, libre de dispersante. Ambas mediciones fueron realizadas en el equipo Zetasizer de Malvern Instruments. Para la fabricación de la suspensión, se empleó un molino de bolas planetario (CT 242 Servitech) con un tiempo de agitación de 15 min.

El diseño experimental bajo el cual se realizó el estudio y análisis reológico de la suspensión se basó en la evaluación de dos factores: carga de sólidos y cantidad de ligante. El primer factor con 3 niveles: 60, 62,5 y $65 \%$ en masa y el segundo factor con 6 niveles: de 5 a 7,5\% en masa, con un aumento de $0,5 \%$. La cantidad de dispersante se mantuvo constante, de acuerdo con el trabajo de Moreno [8], que afirma que $1 \mathrm{~g}$ es la cantidad necesaria para mantener una suspensión dispersa de alúmina.

En total fueron 18 formulaciones diferentes, cada una de ellas con su respectiva réplica para un total de 36 muestras. Para llegar a dicho diseño experimental, se evaluó inicialmente la importancia de incluir o no una carga máxima de sólidos del 70\% y el empleo o no de antiespumante en la formulación de la suspensión.

La definición de este diseño experimental busca principalmente analizar y cuantificar el efecto que implica aumentar la carga de sólidos, tanto en la reología de la suspensión como en la resistencia mecánica de las espumas de alúmina a producir. Con la variación de la cantidad de ligante, se espera obtener la combinación más adecuada a partir de resultados de pseudoplasticidad y tixotropía.

Las mediciones reológicas se hicieron en un viscosímetro (marca ThermoHaake, modelo DC10), empleando la geometría de cilindros concéntricos, adecuada para altas tasas de cizallamiento y altas viscosidades.

A través del software, que evalúa y analiza los datos proporcionados por el viscosímetro, es posible obtener los modelos reológicos que permiten caracterizar la naturaleza reológica de las suspensiones. La obtención de estos modelos es importante para así tener un control sobre la viscosidad aparente $\left(\eta_{\mathrm{Ap}}\right)$, que depende de las diferentes tasas de cizallamiento $\left(\tau_{\mathrm{y}}\right)$ a la que es expuesto el fluido [9]. 
El modelo reológico que mejor representó el comportamiento reológico de las suspensiones fabricadas fue el de Herschel Bulkley, (el cual es una combinación entre la Ley de Potencia o también llamado como el modelo de Ostwald Waele, y el modelo de Plástico de Bingham) [10], definido por la ecuación 1:

$$
\tau=\tau_{o}+k \gamma^{n}
$$

Donde:

$\tau_{\mathrm{o}}$, es la tasa de cizallamiento mínima para que ocurra deformación en el fluido y por tanto comience a fluir,

$\mathrm{k}$, se denomina como índice de consistencia, y representa una medida indirecta de la viscosidad. A medida que el fluido presenta una mayor espesura o mayor viscosidad, $k$ toma valores mayores,

$\eta$, se denomina como índice de comportamiento, el cual define el desvío existente entre el fluido medido con el de un fluido newtoniano, siendo que si $\eta$ es menor que la unidad se refiere a un fluido pseudoplástico y si es mayor a la unidad se refiere a un fluido dilatante.

$\gamma$, es la tasa de deformación del fluido por efecto de la tensión aplicada.

El modelo de Cross se describe por la ecuación 2:

$$
\tau=\frac{\dot{\gamma} \cdot\left(\eta_{\infty}+\left(\eta_{o}-\eta_{\infty}\right)\right)}{\left(1+\left(\begin{array}{c}
\dot{\gamma} \\
\gamma_{b}
\end{array}\right)^{n}\right)}
$$

Donde:

$\eta_{\mathrm{o}}$, es la viscosidad inicial del fluido a deformación cero

$\eta_{\infty}$, es la viscosidad en el infinito o viscosidad limite, a una alta tasa de deformación

$\gamma_{\mathrm{b}}$, es el coeficiente de Cross

$\gamma$, es la tasa de deformación del fluido por efecto de la tensión aplicada

\subsection{Fabricación de la espuma cerámica por el método de la réplica}

Se escogieron un grupo de formulaciones que cumplieran con los parámetros establecidos en la Tabla 3 , los cuales compromete a dichas suspensiones a presentar un comportamiento ideal a lo largo del proceso de fabricación de las espumas cerámicas, mediante el método de réplica.

Para la fabricación de las espumas cerámicas de alúmina por el método de réplica, se emplearon espumas de poliuretano (PU) de 10 y 20 ppi (pores per inches) (Foam Partner, Fritz \& Nauer), con dimensiones de $2,3 \times 2,3 \times 2,0 \pm 0,1 \mathrm{~cm}$. Las muestras fueron impregnadas en la suspensión. La remoción del exceso de suspensión del cuerpo poroso se realizó manualmente. Las muestras se dejaron secar a temperatura ambiente durante un periodo de $24 \mathrm{~h}$. Posteriormente se realizó una etapa de recubrimiento de la superficie externa de la espuma mediante el mecanismo de spray. Las piezas se dejaron secar a temperatura ambiente por un periodo de mínimo $3 \mathrm{~h}$.

Teniendo las espumas en verde, se dio paso al tratamiento térmico dividido en dos etapas. En la primera de ellas, se eliminaron del cuerpo poroso los materiales orgánicos presentes: PU y aditivos; la operación se realizó a una tasa de $0.45^{\circ} \mathrm{C} / \mathrm{min}$ desde temperatura ambiente hasta $450^{\circ} \mathrm{C}$. Enseguida, se elevó la tasa de calentamiento a $3^{\circ} \mathrm{C} / \mathrm{min}$ hasta alcanzar los $1200^{\circ} \mathrm{C}$ (etapa de presinterización), temperatura a la que permaneció constante durante un periodo de $2 \mathrm{~h}$; finalmente se procedió a un enfriamiento controlado de las estructuras en el horno a una tasa comprendida entre 10 y $15{ }^{\circ} \mathrm{C} / \mathrm{min}$ hasta alcanzar la temperatura ambiente. Para este primer ciclo térmico, se empleó el horno Linn ElecktroTerm KK 260. Las estructuras fueron trasladadas a un horno tubular, en el cual se completa la sinterización de las espumas cerámicas; el ciclo comenzó a una tasa de $12^{\circ} \mathrm{C} / \mathrm{min}$ (mínima tasa de calentamiento a la que el horno opera) hasta $\operatorname{los} 1600^{\circ} \mathrm{C}$, donde permaneció por $3 \mathrm{~h}$ y se procedió al 
enfriamiento a una tasa entre $7-9^{\circ} \mathrm{C} / \mathrm{min}$ hasta alcanzar la temperatura ambiente. Se empleó el horno tubular Micropyretics Heaters Internacional BPAN.

Tabla 3: Parámetros de selección de la formulación más adecuada en la fabricación de espumas cerámicas por el método de réplica.

\begin{tabular}{c|l|c}
\hline PARÁMETRO & \multicolumn{1}{c|}{ CARACTERÍSTICA } & ETAPA QUE INFLUENCIA \\
\hline \multirow{2}{*}{ Alta pseudoplasticidad } & $\begin{array}{c}\text { Asegura que la suspensión va a fluir por todo } \\
\text { el cuerpo volumétrico al disminuir su viscosi- } \\
\text { dad a medida que es aplicado el esfuerzo. } \\
\text { Cuando cesa el esfuerzo aumenta la viscosi- } \\
\text { dad lo que facilita la adherencia de la suspen- } \\
\text { sión a las paredes celulares. }\end{array}$ & Impregnación \\
\hline Alta tixotropía & $\begin{array}{l}\text { Asegura la facilidad con la que la suspensión } \\
\text { va retomar su viscosidad original después de } \\
\text { terminada la etapa de impregnación. Le brin- } \\
\text { da a la espuma cerámica una alta consistencia } \\
\text { y resistencia. }\end{array}$ & Impregnación \\
\hline \multirow{2}{*}{$\begin{array}{c}\text { Alto contenido de sólidos/ } \\
\text { Baja cantidad de ligante }\end{array}$} & $\begin{array}{l}\text { Entre mayor sea su valor mayor es su resis- } \\
\text { tencia mecánica. Evita la presencia de una } \\
\text { alta densidad de grietas al disminuir la canti- } \\
\text { dad de solvente que se evapora. }\end{array}$ & Tratamiento térmico \\
\hline
\end{tabular}

\subsection{Caracterización de las espumas cerámicas de alúmina}

Se realizó un ensayo de compresión en una máquina de ensayos universales (EMIC DL2000), usando muestras de espumas cerámicas con dimensiones de 2,3 $32,3 \times 2,0 \mathrm{~cm}$. Las muestras, en total 4 ( 2 de cada una de las diferentes espumas: 10 y 20 ppi), fueron sometidas a una compresión de placas paralelas, con control de desplazamiento. La primera prueba se hizo a una velocidad de desplazamiento de $0,5 \mathrm{~mm} / \mathrm{min}$ con el fin de comparar la mayor resistencia mecánica de dos de las formulaciones más resistentes al primer ciclo térmico. Posteriormente con la formulación seleccionada, se comparó su resistencia mecánica a dos velocidades de desplazamiento: 0,5 y $1 \mathrm{~mm} / \mathrm{min}$, para así apreciar el efecto de ésta variable sobre la resistencia a la compresión de las muestras.

Mediante un microscopio electrónico de barrido (MEB, Philips XL 30), cuyo máximo potencial de energía del cañón de electrones es de $30 \mathrm{kV}$, se obtuvieron imágenes con aumentos entre $15 \mathrm{y}$ $4000 \times$. Las muestras fueron recubiertas por una película delgada de oro. En las imágenes fue posible apreciar defectos microestructurales, diámetro de celda y espesor de pared de las celdas. Por medio del software Imago (ESSS) fue posible determinar el grado de porosidad que presentaban las paredes de la espuma cerámica. El análisis fue realizado sobre imágenes obtenidas de MEB a un aumento de $2000 \times$. Fueron analizadas 4 imágenes de MEB, cada pareja correspondiente a 2 tomas de las diferentes espumas: 10 y 20 ppi.

A través de un equipo diseñado en el laboratorio de combustión (LABCET/UFSC), fue posible caracterizar la permeabilidad de las espumas de alúmina producidas, a través de la medición de la diferencia de presión entre dos puntos ubicados en la entrada y salida de $\mathrm{N}_{2}$, al pasar por la estructura porosa. Se utilizó un multímetro de presión (Omega PX137-015AV) y un fluxómetro (Omega FMA1720, EUA), con el que se tenía una medida del flujo en L/min que atravesaba la muestra. Las mediciones se realizaron a temperatura ambiente $\left(25^{\circ} \mathrm{C}\right)$. Para determinar las constantes Darciana y noDarciana, $\mathrm{k}_{1} \mathrm{y} \mathrm{k}_{2}$ respectivamente, se emplearon los datos proporcionados de la medición y la ecuación para fluidos compresibles de Forchheimer. 
La densidad relativa, $\rho_{\mathrm{r}}$, fue calculada por la relación existente entre la densidad del material celular, otorgada por el fabricante y la densidad del sólido, determinada por picnometría en helio. La ecuación 3, muestra esta relación:

$$
\rho_{r}=\left(\frac{\rho_{\text {cuerpo_celular }}}{\rho_{\text {solido }}}\right)
$$

Para las espumas de alúmina, la densidad del material celular fue calculada por medio de la definición de densidad: masa/volumen, lo que fue equivalente a medir el masa de cada una de las muestras y medir cada una de las dimensiones para obtener el volumen. Para la densidad del sólido, se asumió la densidad del material puro, debido a la alta pureza $(99,8 \%)$ del polvo cerámico. La porosidad $(\varepsilon)$ total de la cerámica celular, fue calculada a través de la relación:

$$
\varepsilon=1-\rho_{r}
$$

\section{RESULTADOS}

\subsection{Análisis de tamaño de partícula y potencial zeta de la alúmina}

La Figura 1 muestra los resultados obtenidos para la determinación del tamaño de partícula del polvo de alúmina empleado.

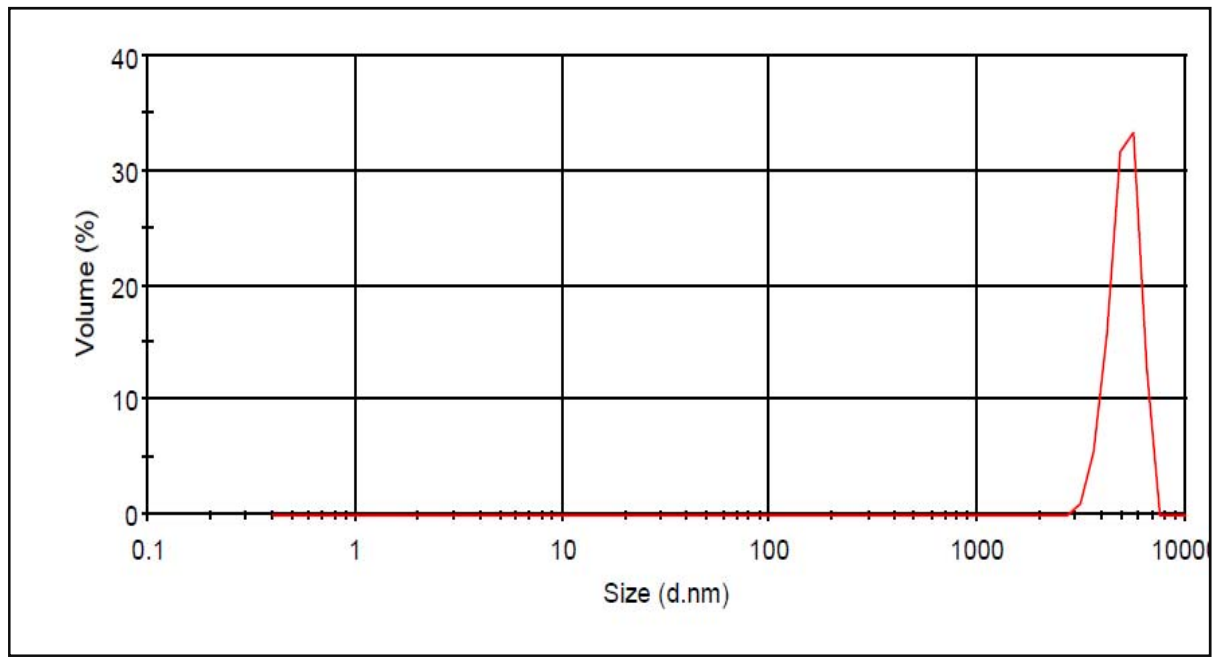

Figura 1: Distribución de tamaño de partícula.

La Figura 1 evidencia una curva monodispersa, ubicándose el pico máximo en $\sim 5,3 \mu \mathrm{m}$, correspondiente a un polvo de escala fina. Se registró una viscosidad de la solución equivalente a 0,89 $\mathrm{mPa} \cdot \mathrm{s}$, correspondiente a una suspensión acuosa diluida.

En la Figura 2 se muestra el resultado obtenido de la medición del potencial zeta de la suspensión de alúmina.

Como se puede observar, el punto isoeléctrico de la alúmina se encuentra en un $\mathrm{pH}$ igual a 4,34. Cerca de éste valor, la solución va experimentar el fenómeno de floculación. El valor del $\mathrm{pH}$ de la suspensión seleccionada debe ser mayor o igual a 6 , lo que corresponde a un potencial zeta entre 30 a $-40 \mathrm{mV}$, rango en el que se asegura una total dispersión de las partículas y por tanto una estabilidad al sistema [11]. 


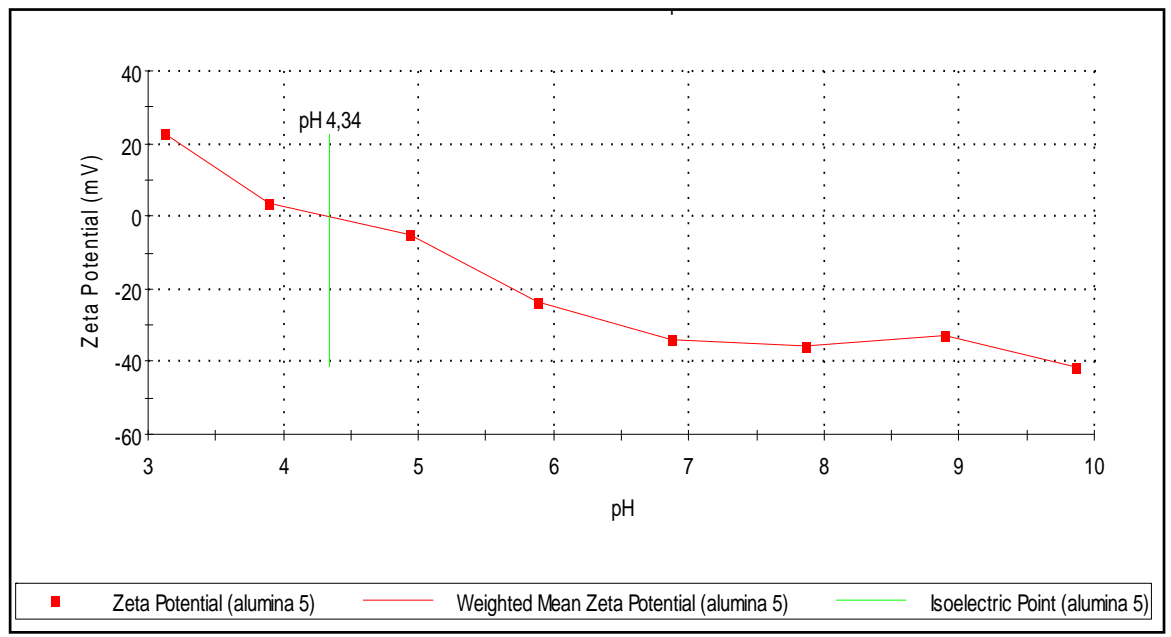

Figura 2: Determinación del punto isoeléctrico de la alúmina con respecto al pH.

\subsection{Formulaciones de la suspensión de alúmina seleccionadas}

En la Tabla 4 se encuentran los resultados más satisfactorios obtenidos del estudio reológico realizado, de acuerdo con los parámetros de la Tabla 3. Las formulaciones seleccionadas se identifican por las primeras dos columnas, con sus respectivos valores de viscosidad inicial, viscosidad infinita o bajo altas tasas de cizallamiento y la tixotropía. Las Figuras 3 y 4 son las gráficas de flujo y tixotropía de las dichas suspensiones.

Tabla 4: Formulaciones escogidas de la suspensión de alúmina.

\begin{tabular}{c|c|c|c|c}
\hline $\begin{array}{c}\text { CARGA DE } \\
\text { SÓLIDOS } \\
\text { [\%Masa] }\end{array}$ & $\begin{array}{c}\text { CANTIDAD DE } \\
\text { LIGANTE [g] }\end{array}$ & $\begin{array}{c}\text { VISCOSIDAD } \\
\text { INICIAL [mPa·s] }\end{array}$ & $\begin{array}{c}\text { VISCOSIDAD INFINITA } \\
{[\mathrm{mPa} \cdot \mathbf{s}]}\end{array}$ & $\begin{array}{c}\text { TIXOTROPÍA } \\
{\left[\mathrm{Pa} \cdot \mathbf{s}^{-1} \text { ] }\right.}\end{array}$ \\
\hline $65,0 \%$ & 6,5 & 478,58 & 55,05 & 7612 \\
\hline $62,5 \%$ & 6,5 & 164,78 & 21,12 & 6401 \\
\hline $62,5 \%$ & 7,5 & 482,98 & 16,49 & 9381 \\
\hline
\end{tabular}

Las suspensiones de la primera y tercera fila de la Tabla 4, fueron analizadas por el modelo de Herschel-Bulkey, ecuación 1 y la suspensión restante correspondió al modelo de Cross, ecuación 2. Los valores de viscosidad inicial y en el infinito fueron calculados a partir de estas ecuaciones. Los valores de la tixotropía fueron determinados por el software del viscosímetro empleado.

Las Figuras 3 y 4, evidencian el comportamiento pseudoplástico y tixotrópico, respectivamente, de las formulaciones escogidas.

Como se puede apreciar, las tres formulaciones presentaron viscosidades iniciales entre los 76000 a $15000 \mathrm{mPa} \cdot \mathrm{s}$ y viscosidades en el infinito en un rango de los 55 a $3 \mathrm{mPa} \cdot \mathrm{s}$ (Figura 3 ). Comparando la diferencia entre los valores iniciales y finales de la viscosidad, se puede afirmar que las suspensiones presentaron una alta pseudoplasticidad. En la Figura 4 es posible observar grandes áreas entre las curvas, correspondiendo a valores entre los 6400 a $9400 \mathrm{~Pa} \cdot \mathrm{s}^{-1}$ de tixotropía. La de $62,5 \%$ $7,5 \mathrm{~g}$ obtuvo la mayor tixotropía, y la de $62,5 \%$ - 6,5 g fue la de menor tixotropía.

En respuesta a esta similitud en el comportamiento pseudoplástico y tixotrópico de las suspensiones, se decidió que el siguiente filtro de selección fuese la resistencia mecánica durante la etapa de presinterización de las espumas cerámicas en verde. La Figura 5 muestra los resultados obtenidos, donde se evaluó el número de muestras resistentes al primer ciclo térmico, partiendo de 6 muestras iniciales para cada una de las tres formulaciones. 


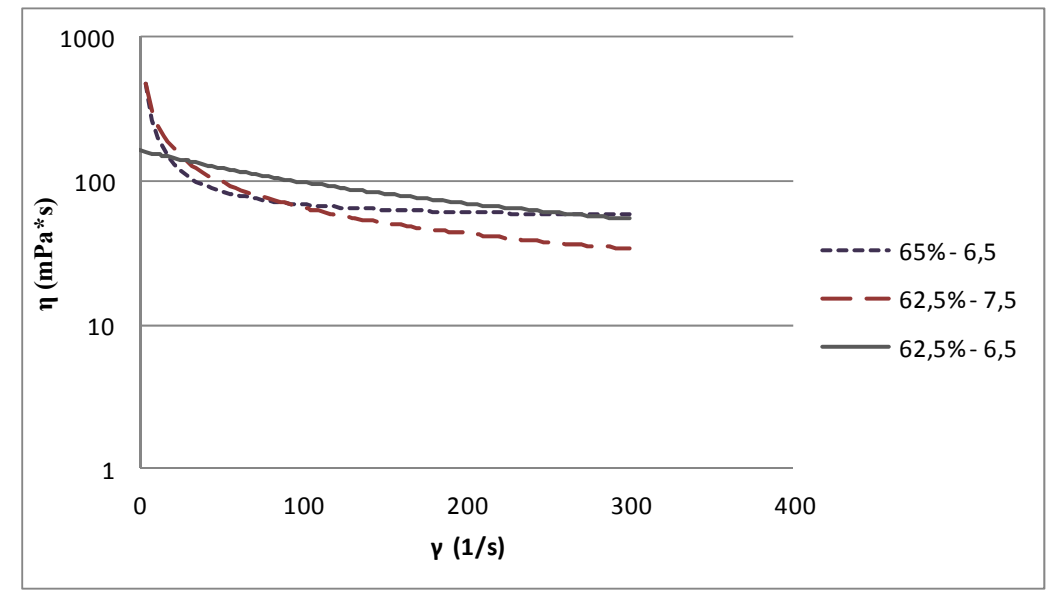

Figura 3: Viscosidad vs tasa de cizallamiento de las formulaciones escogidas de la suspensión de alúmina.

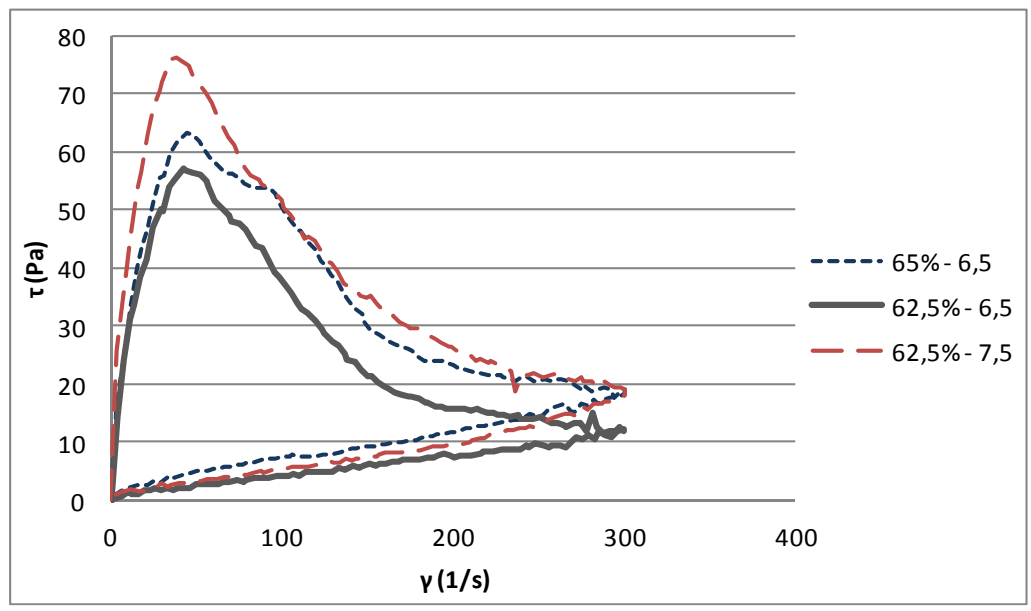

Figura 4. Tixotropía de las formulaciones escogidas de la suspensión de alúmina.

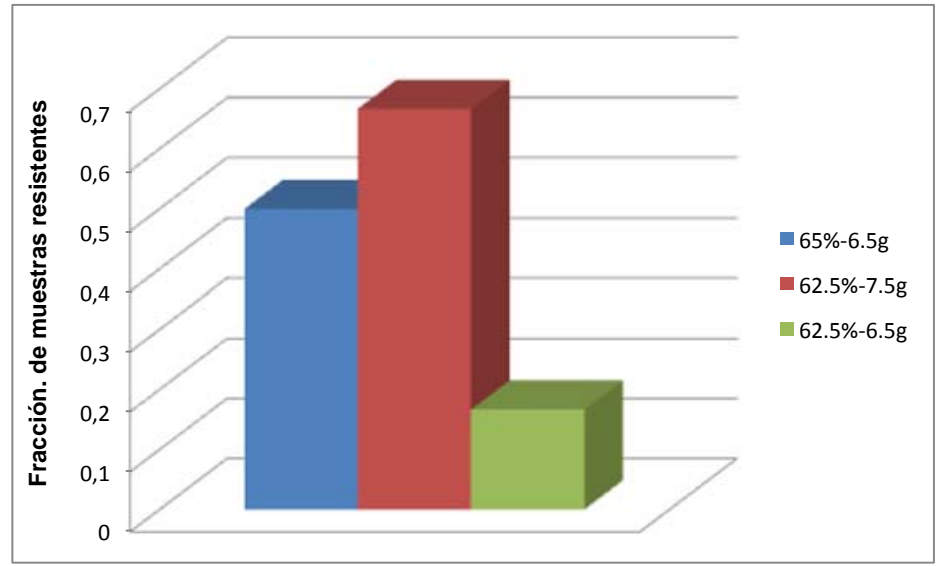

Figura 5: Resistencia al ciclo de pre sinterización de las diferentes formulaciones escogidas

En esta prueba se consideraron como muestras resistentes aquellas que retuvieron el $100 \%$ de la estructura, o en otras palabras, que tuvieron retención de forma. En la Figura 5 es posible apreciar una relativa mayor resistencia al primer ciclo térmico, de las formulaciones con $65 \%-6,5 \mathrm{~g}$ y la de 62,5\%-7,5 g de ligante respectivamente. Partiendo de este resultado, se descartó la formulación de mínima resistencia y se dio paso a la elección final de la formulación más adecuada mediante un test de compresión. 


\subsection{Resistencia a la compresión}

Se comparó la resistencia mecánica de las dos formulaciones restantes, con una velocidad de desplazamiento de $0,5 \mathrm{~mm} / \mathrm{min}$. Las Figuras 6 y 7 muestran estos resultados para muestras de 10 y 20 ppi respectivamente.

En la Figura 6 se evidencia la mayor resistencia a la compresión que presentan las estructuras con formulación de $65 \%$ de sólidos y $6,5 \mathrm{~g}$ de ligante, resultado que respalda afirmaciones encontradas en la literatura $[3, \underline{8}, \underline{12]}$. La mayor resistencia a la compresión alcanzada por esta suspensión fue de 0,060 MPa, mientras que la otra formulación $(62,5 \%, 7,5 \mathrm{~g})$ fue de 0,046 $\mathrm{MPa}$.

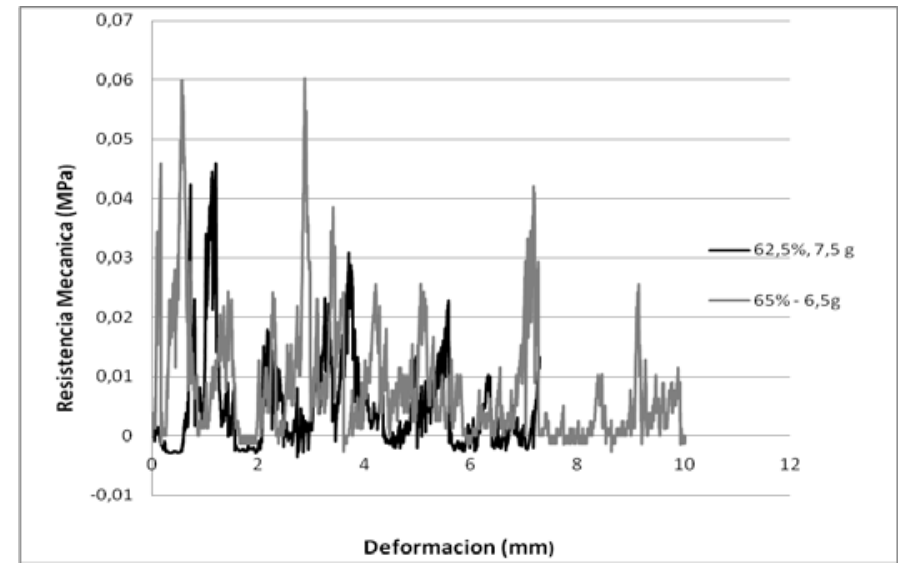

Figura 6: Resistencia a la compresión, a una velocidad de desplazamiento de $0,5 \mathrm{~mm} / \mathrm{min}$, para espumas de 10 ppi.

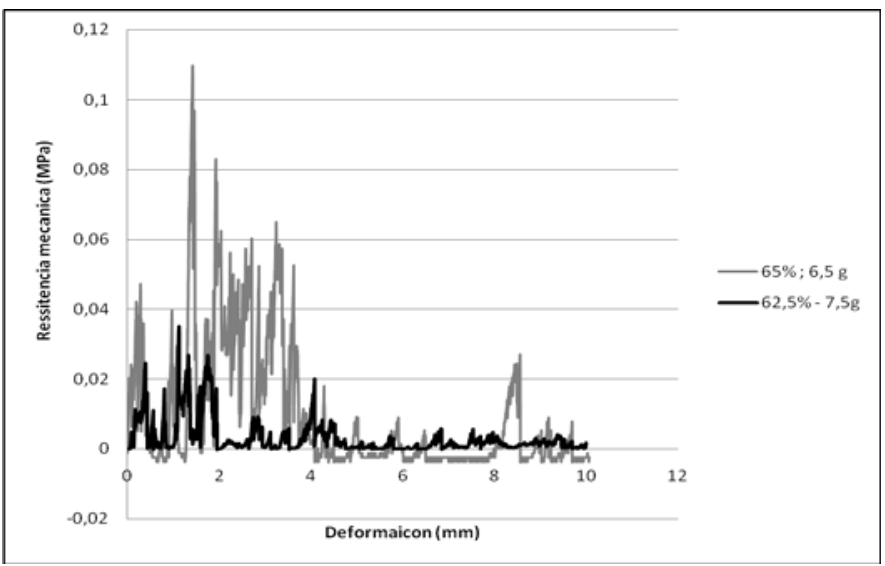

Figura 7: Resistencia a la compresión a una velocidad de desplazamiento de $0,5 \mathrm{~mm} / \mathrm{min}$, para espumas de 20 ppi.

Como se observa en la Figura 7, para las espumas de 20 ppi se repite la misma tendencia, la formulación con mayor carga de sólidos presenta la mayor resistencia a la compresión. Los mayores valores de resistencia mecánica alcanzados fueron 0,11 y $0,035 \mathrm{MPa}$ para las formulaciones de $65 \% \mathrm{y}$ $62,5 \%$ respectivamente. Los anteriores resultados dieron paso a la selección final de la formulación con la mayor carga de sólidos. Se midió su pH y éste fue de 8,4, valor que confirma la buena estabilidad de la suspensión al tener partículas totalmente dispersas en el sistema (Figura 2).

Para esta última formulación se comparó la resistencia a la compresión a diferentes velocidades de desplazamiento, esto con el fin de apreciar cómo influía esta variable en la resistencia de la estructura porosa. Por causa de una sinterización incompleta de las últimas muestras (tiempo insuficiente de la meseta en el segundo ciclo térmico), se obtuvieron resultados no esperados para la velocidad de 1 $\mathrm{mm} / \mathrm{min}$. Las Figuras 8 y 9 revelan lo ocurrido. 


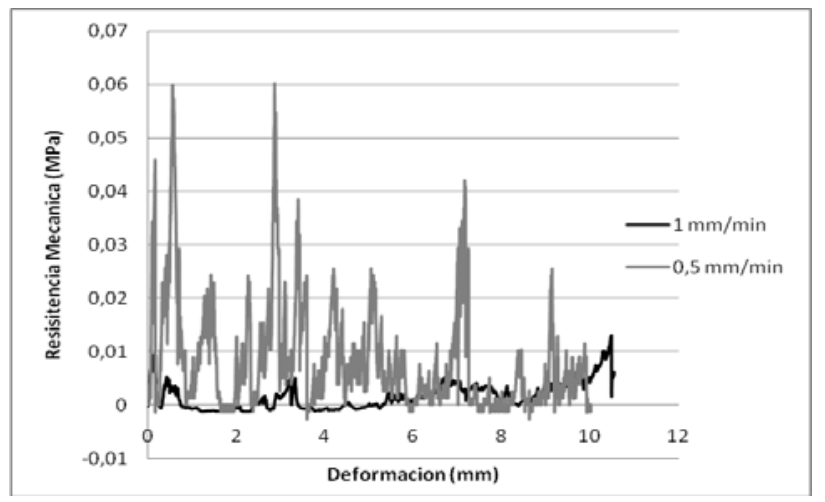

Figura 8: Resistencia a la compresión de muestras de 10 ppi con $65 \%$ de sólidos, a dos velocidades de desplazamiento: 0,5 y $1 \mathrm{~mm} / \mathrm{min}$.

Para este grupo de muestras, la resistencia máxima alcanzada antes de comenzar la deformación fue de $0,06 \mathrm{MPa}$ a $0,5 \mathrm{~mm} / \mathrm{min}$, mientras que a una velocidad de $1 \mathrm{~mm} / \mathrm{min}$, fue de $0,01 \mathrm{MPa}$.

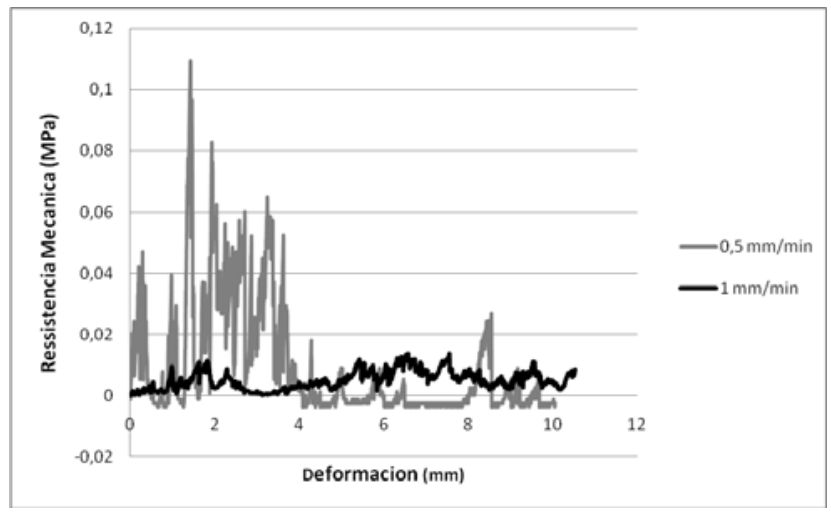

Figura 9: Resistencia a la compresión de muestras de 20 ppi con $65 \%$ de sólidos, a diferentes velocidades de desplazamiento: 0,5 y $1 \mathrm{~mm} / \mathrm{min}$.

En esta última gráfica, la mayor resistencia mecánica de nuevo la presentó la muestra a la menor velocidad, equivalente a $0,11 \mathrm{MPa}$, mientras que a $1 \mathrm{~mm} / \mathrm{min}$, dicho valor se encontró en 0,008 MPa.

La anterior situación, se encuentra totalmente justificada al analizar las imágenes proporcionadas por MEB.

\subsection{Análisis morfológico y microestructural}

La Figura 10-a evidencia el resultado de una sinterización incompleta. Como se puede apreciar, las partículas de alúmina no consiguieron unirse completamente por presentarse un tiempo insuficiente de meseta durante el proceso de sinterización (segundo ciclo térmico), razón por la cual se obtuvo una mínima densificación del material con una alta porosidad en las paredes de la espuma cerámica (parámetro que fue analizado a través de análisis de imagen). A raíz de este hecho, al presentarse esta falla microestructural en las muestras que experimentaron el ensayo de compresión, su resistencia mecánica fue deficiente (Figuras 8 y 9).

En la Figura 10-b se puede apreciar uno de los hilos de la celda con un poro interno por donde salen los productos de la pirolisis del material polimérico. Este es un defecto microestructural típico del método de la réplica. Por su parte, la Figura 10-c, muestra una alta microporosidad y grietas en las paredes de la espuma de alúmina de 10 ppi. Esta imagen de nuevo justifica, la baja resistencia mecánica que esta presentó. Por medio de esta herramienta, también fue posible determinar el diámetro medio de celda y el grosor de las paredes cerámicas de la espuma, cuyos resultados se encuentran en la Tabla 5. Para ésta medición se contó con dos muestras de cada una de las densidades lineales $(10 \mathrm{y}$ $20 \mathrm{ppi})$. 


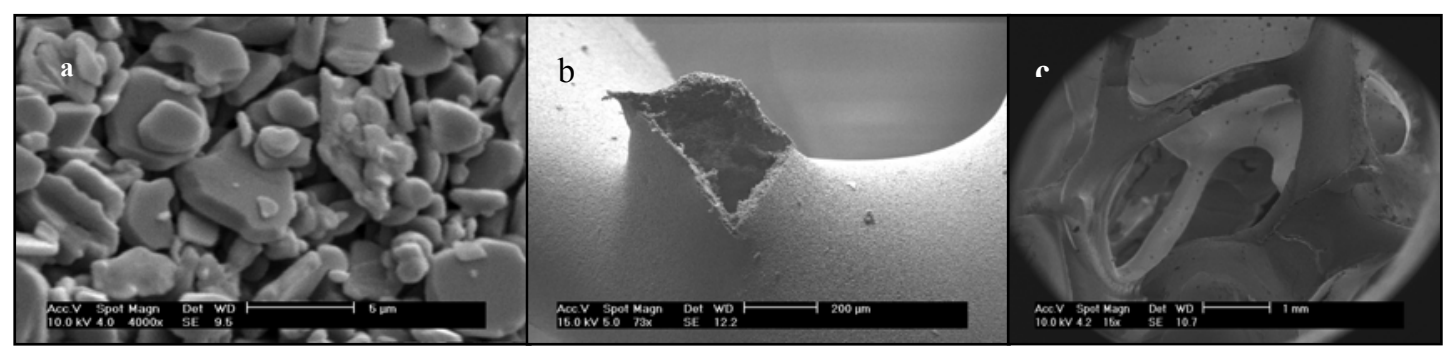

Figura 10: Imágenes obtenidas por MEB de las espumas cerámicas de alúmina. a) Muestra de 20 ppi, 65\% de sólidos a 4000x. b) Muestra de 10 ppi, 65\% de sólidos a 73x. c) Muestra de 10 ppi a 15x.

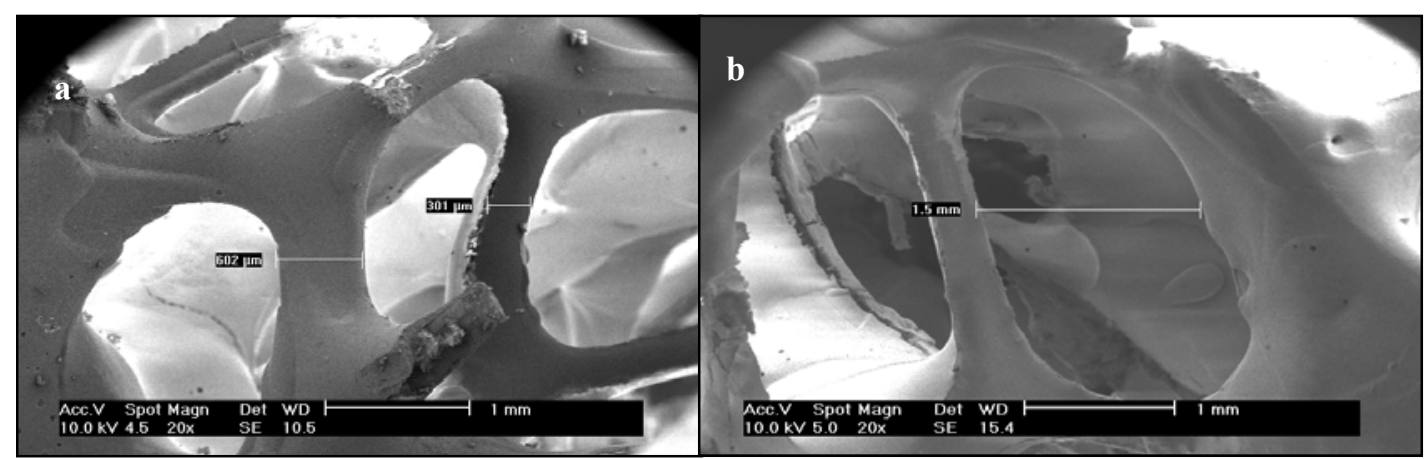

Figura 11: Medidas de grosor de pared y diámetro de celda por MEB a un aumento de 20x. a) Medición grosor de pared celular, espuma de $\mathrm{Al}_{2} \mathrm{O}_{3}$ de 10 ppi. b) Medición diámetro de celda, espuma de $\mathrm{Al}_{2} \mathrm{O}_{3}$ de 20 ppi.

Tabla 5: Resumen mediciones de diámetro de la celda y grosor de la pared cerámica, de las espumas alúmina de 10 y 20 ppi.

\begin{tabular}{c|c|c|c}
\hline $\begin{array}{c}\text { TAMAÑO } \\
\text { DE CELDA } \\
\text { [ppi] }\end{array}$ & $\begin{array}{c}\text { DIÁMETRO MEDIO DE LA } \\
\text { CELDA GRANDE [mm] }\end{array}$ & $\begin{array}{c}\text { DIÁMETRO MEDIO DE LA } \\
\text { CELDA PEQUEÑA [mm] }\end{array}$ & $\begin{array}{c}\text { GROSOR DE LA } \\
\text { PARED CELULAR } \\
\text { [mm] }\end{array}$ \\
\hline $10 \mathrm{ppi}$ & $2,47 \pm 0,14$ & $1,34 \pm 0,3$ & $0,71 \pm 0,45$ \\
\hline $20 \mathrm{ppi}$ & $2,35 \pm 0,12$ & $1,6 \pm 0,1$ & $0,35 \pm 0,15$ \\
\hline
\end{tabular}

La Tabla 5 resume las mediciones de diámetro de la celda y grosor de la pared cerámica de las espumas alúmina de 10 y 20 ppi. El diámetro de las celdas grandes es mayor para las espumas de 10 ppi en comparación a las de 20 ppi (aunque la diferencia no es muy significativa), hecho que se justifica en la menor densidad lineal de una con respecto a la otra. Sucede lo contrario con el diámetro de los poros pequeños, el cual resulta ser mayor para la espuma de 20 ppi que para la de 10 ppi. El grosor de las paredes cerámicas resulta ser mayor para la espuma de $10 \mathrm{ppi}$, hecho que de nuevo se justifica en el menor grado de porosidad lineal.

\subsection{Porosidad de las paredes y densidad relativa}

La porosidad presente en las paredes sólidas de las espumas cerámicas de alúmina de 10 y 20 ppi, es revelada por las regiones más claras de la Figura 12. 


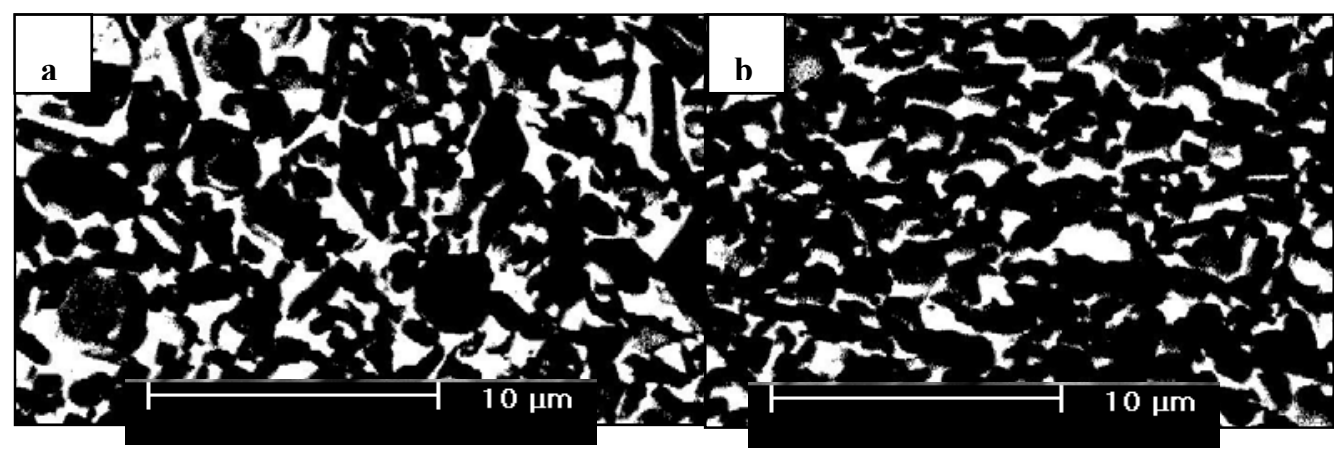

Figura 12: Porosidad de las paredes sólidas de una espuma de alúmina con sinterización incompleta. a) 10 ppi-65\% sólidos; b) 20 ppi- $65 \%$ sólidos.

Para la espuma de 10 ppi se obtuvo una porosidad del $28 \%$ y la de 20 ppi de $26,5 \%$. Dichos valores son muy elevados, pues para una estructura completamente sinterizada, el porcentaje de porosidad debe ser menor al 10\% [9]. Esta situación de nuevo respalda la presencia de una sinterización incompleta.

La Tablas 6 muestra los valores obtenidos de densidad relativa y porosidad, calculados para las espumas de PU y de alúmina, para las dos porosidades lineales: 10 y 20 ppi.

Tabla 6: Densidad relativa y porosidad de las espumas de PU y de las replicas de alúmina de 10 y 20 ppi.

\begin{tabular}{c|c|c|c|c}
\hline $\begin{array}{c}\text { TIPO DE } \\
\text { ESPUMA }\end{array}$ & $\begin{array}{c}\text { DENSIDAD DEL } \\
\text { MATERIAL CELULAR } \\
{\left[\mathrm{g} / \mathrm{cm}^{3}\right]}\end{array}$ & $\begin{array}{c}\text { DENSIDAD DEL } \\
\text { SÓLIDO } \\
{\left[\mathrm{g} / \mathrm{cm}^{3}\right]}\end{array}$ & $\begin{array}{c}\text { DENSIDAD } \\
\text { RELATIVA }\end{array}$ & $\begin{array}{c}\text { POROSIDAD } \\
\text { [\%] }\end{array}$ \\
\hline $\mathrm{PU}, 10 \mathrm{ppi}$ & 0,025 & 0,94 & 0,026 & 97,3 \\
\hline $\mathrm{PU}, 20 \mathrm{ppi}$ & 0,025 & 1,04 & 0,024 & 97,6 \\
\hline $\mathrm{Al}_{2} \mathrm{O}_{3}, 10 \mathrm{ppi}$ & $0,38 \pm 0,064$ & 3,98 & $0,095 \pm 0,064$ & $90,4 \pm 0,064$ \\
\hline $\mathrm{Al}_{2} \mathrm{O}_{3}, 20 \mathrm{ppi}$ & $0,433 \pm 0,075$ & 3,98 & $0,109 \pm 0,075$ & $89,1 \pm 0,075$ \\
\hline
\end{tabular}

En las espumas de alúmina la de 10 ppi resultó tener mayor porosidad que la de 20 ppi en un $1,3 \%$. Una causa puede ser una mayor presencia de celdas cerradas en la de 20 ppi. A medida que el tamaño de celda disminuye, se hace más vulnerable a que termine recubierto por la suspensión durante el proceso de impregnación a pesar de realizar la etapa de soplado. La diferencia de porosidad entre la espuma de PU de 10 ppi con su réplica, fue del 6,9\%, y para la pareja de $20 \mathrm{ppi}$, fue del 8,5\%. Teniendo en cuenta el rango de porosidad apropiado para cerámicas celulares, el cual se encuentra entre el 70 y $90 \%$ [3], las espumas de alúmina fabricadas tienen una porosidad aceptable.

\subsection{Permeabilidad}

La prueba se realizó sobre una muestra de una espuma de alúmina de 10 ppi. La Figura 13 muestra el gráfico a partir del cual fue posible determinar las constantes de permeabilidad Darciana y noDarciana, $\mathrm{k}_{1}=4,86^{10-8} \mathrm{~m}^{2}$ y $\mathrm{k}_{2}=0,131 \mathrm{~m}$, respectivamente, así como una constante de Forchheim $\mathrm{F}_{\mathrm{o}}=$ $7,02 \cdot 10^{-3}$.

En vista de que el $F_{o}$ obtenido resultó ser menor a la unidad, se tiene que la diferencia de presión total presente durante la realización de la prueba, se debió a la resistencia impuesta por las fuerzas viscosas del sistema. A partir de los datos de permeabilidad para la espuma polimérica de 10 ppi obtenidos por Moreno [5], fue posible comparar la diferencia de permeabilidad entre ésta última y su réplica. El flujo medio volumétrico de gas que soportó la espuma de PU fue de $0,0003 \mathrm{~m}^{3} / \mathrm{s}$, mientras que la de alúmina fue de $0,000186 \mathrm{~m}^{3} / \mathrm{s}$. La diferencia de permeabilidad entre las dos estructuras es del $38 \%$, hecho que de nuevo refleja celdas obstruidas y paredes mucho más gruesas, que generan mayor fricción. 


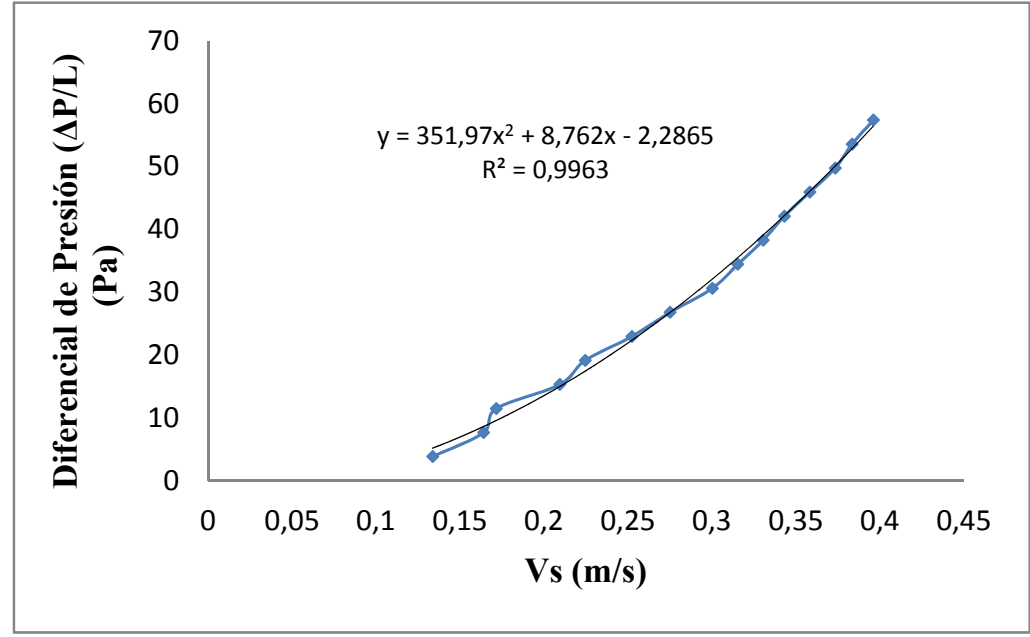

Figura 13: Determinación de las constantes de permeabilidad.

\section{DISCUSIÓN}

El fenómeno que se presentó durante la prueba a la resistencia mecánica al primer ciclo térmico o presinterización de las estructuras cerámicas, se pudo explicar en la baja dispersión que presentó el ligante en el $100 \%$ de la suspensión. Esta situación conllevó a que cuando se comenzó a evaporar el solvente, las partículas de alúmina se adhirieron fuertemente y las partículas de ligante no se encontraban en ese punto para formar puentes orgánicos entre ellas para dar flexibilidad y resistencia a la estructura cerámica en la medida que aumentaba la temperatura [12-15].

En la caracterización a la resistencia mecánica a la compresión de las espumas cerámicas de alúmina, las muestras de 20 ppi presentaron mayor resistencia mecánica en comparación a las de 10 ppi, lo cual se puede explicar en la mayor área reticulada que presentan estas espumas, pues de este modo puede distribuirse más fácil y eficientemente las fuerzas que están siendo aplicadas sobre éstas. El hecho de tener paredes más gruesas no implica que su resistencia vaya a ser mayor, pues como se demostró en la sección 3.3, entre la pared celular sea más gruesa, más defectos microestructurales puede llegar a tener (grietas, microporos, orificios), causando un fractura de la estructura rápidamente. Con paredes más finas se da paso a una estructura más reticulada y por tanto con una mayor capacidad en la distribución de fuerzas [16].

En la etapa del proceso de caracterización, en la que se compara la máxima resistencia mecánica soportada por la formulación escogida al variar la velocidad de desplazamiento, se espera que con una velocidad de mayor rapidez el material se comporte más resistente en respuesta a que el impacto es proporcional a la velocidad aplicada y por consiguiente la fuerza máxima soportada fuese mayor [9,17]. Dicha situación no fue la encontrada durante el experimento debido a la presencia de una sinterización incompleta, lo cual conllevó a una mínima coalición de las partículas de alúmina, dejando microporos sin cerrar en las paredes celulares y finalmente generando estructuras frágiles.

Con respecto a los resultados de porosidad, se pudo determinar que éste parámetro es inferior en las espumas de alúmina en comparación a las de Poliuretano (PU), a causa de presentar celdas cerradas y paredes más gruesas, brindando así una mayor obstrucción de la abertura total de la celda adyacente.

\section{CONCLUSIONES}

Con base en los resultados obtenidos y en los analisis realizados enfrentados con los de la literatura, se llegaron a las siguientes conclusiones:

- Las características reológicas que debe presentar una suspensión para ser empleada en el método de la réplica son: alta pseudoplasticidad, alta tixotropía, alto contenido de sólidos y la menor cantidad posible de ligante.

- Se obtuvo una baja resistencia mecánica de las estructuras en la etapa de presinterización, debido a la ausencia de plastificante en la formulación de la suspensión, lo cual causó una 
mínima flexibilidad en los hilamentos de la estructura que finalmente llevó al colapso de la misma.

- Una sinterización incompleta se manifiesta en una baja resistencia a la compresión y una alta porosidad en las paredes de la de la espuma cerámica. En las imágenes de MEB, se aprecian las partículas de alúmina sin coalescer y por ende un gran número de microporos.

- Las espumas poliméricas precursoras presentaron mayor porosidad y permeabilidad, en respuesta a la presencia de paredes finas y $99 \%$ de celdas abiertas.

- La mayor resistencia a la compresión la obtuvo la formulación con mayor carga de sólidos, bajo las mismas condiciones de prueba: velocidad, temperatura y tamaño de muestra.

- La baja resistencia mecánica al primer tratamiento térmico del proceso de la réplica, impidió la producción de las muestras de prueba en los quemadores porosos radiantes.

\section{AGRADECIMIENTOS}

A CNPq y CAPES, Brasil, y a COLCIENCIAS, Colombia, por el apoyo financero.

\section{BIBLIOGRAFÍA}

[1] CATC. Clean Air Technology Center. Nitrogen Oxides (NOx), Why and How they are controlled, Research Triangle Park, North Carolina, 1999

[2] INGHAM. D, BEJAN, A., MAMUT, E., et al., Emerging Technologies and Techniques in Porous Media, Netherlands, pp., 367-369, Kluwer Academic Publishers (2004),

[3] SCHEFFLER, M. COLOMBO, P., Cellular ceramics: structure, manufacturing and applications, New York., Wiley-VCH. , 2005.

[4] CATAPAN, R.C., Desenvolvimento experimental de queimadores porosos radiantes a gás natural, Monografia de conclusão de curso, Departamento de Engenharia Mecânica, UFSC, Florianópolis, 2005.

[5] TRIMIS, D., TRUST, F., "Combustion in a porous medium, advances and applications", Science and Technology, v. 121, pp. 153-168, 1996.

[6] SIGMA ALDRICH, disponível em: http://www.sigmaaldrich.com/us-export.html. Citado en junio de 2011.

[7] MONTES, A., Fabricación y caracterización de estructuras celulares cerámicas alúmina para su utilización como medio de filtración., Universidad de Los Andes, Bogotá, 2008.

[8] MORENO, V., Obtenção e caracterização de espumas cerâmicas de alumina para uso como queimadores radiantes., UFSC, Florianópolis, 2009.

[9] HOTZA, D., “Colagem de folhas cerâmicas”, Cerâmica, v. 43, pp. 157-164, 1997.

[10] MORENO, R., Conformado coloidal de materiales cerámicos: métodos avanzados para materiales tradicionales, Instituto de Cerámica y Vidrio, Madrid, 2010.

[11] NASCIMENTO, C.A., Influencia do tamanho de grão da zircônia estabilizada com ítria e das propriedades reológicas de barbotinas anodicas sobre as características microestruturais de filmes de anodo usados em pilhas à combustível de óxido sólido, M.Sc., Departamento de Química, UFMG, Belo Horizonte, 2007

[12] BREZNY, R., GREEN,D., "The effect of cell size on the mechanical behavior of cellular materials”, Acta Metallurgica et Materialia, v. 38, pp. 2517-2526, 1990.

[13] HARDY, D., GREEN, D., "Mechanical properties of partially sintered alumina", Journal of the European Ceramic Society, v. 15, pp. 769-775, 1995.

[14] SOUSA, E., Processamento e caracterização de vitrocerâmico celular do sistema LZSA., UFSC, Florianópolis, 2007

[15] KRISTOFFERSSON, A., RONCARI, E., GALASSI, C., "Comparison of different binders for water-based tape casting of alumina", Journal of the European Ceramic Society, v. 18, pp. 2123-2131, 1998. 
[16] GOMES, M.C., Obtenção e caracterização de laminados vitrocerâmicos do sistema Li2O-ZrO2SiO2-Al2O3 (LZSA) por manufatura de objetos laminados (LOM)., UFSC, Florianópolis, 2008.

[17] JIANG, B., WANG, Z., ZHAO, N., "Effect of pore size and relative density on the mechanical properties of open cell aluminum foams", Scripta Materialia, v. 56, pp. 169-172, 2007.

\section{$\underline{\text { Errata }}$}

Este artigo sofreu a seguinte alteração no dia 21.11.12.

Na figura 13, página 985, onde se lia fórmula:

$$
\begin{gathered}
\text { 1900ralx }{ }^{2}+1900 \text { ralx - 1900ral } \\
R^{2}=1900 \text { ral }
\end{gathered}
$$

Lê-se:

$$
\begin{gathered}
y=351,97 x^{2}+8,762 x-2,2865 \\
R^{2}=0,9963
\end{gathered}
$$

